\title{
The diagnosis of an imperforate anus in female fetuses
}

\author{
Hyun Mi Kim ${ }^{1,2,3}$, Hyun-Hwa Cha ${ }^{1,2,3}$, Jong In Kim ${ }^{2,3}$, Won Joon Seong ${ }^{1,2,3}$, Sook-Hyun Park ${ }^{4}$, Mi Ju Kim ${ }^{1,2,3}$ \\ ${ }^{1}$ Department of Obstetrics and Gynecology, Kyungpook National University Hospital, Daegu, Korea \\ ${ }^{2}$ Department of Obstetrics and Gynecology, Kyungpook National University Chilgok Hospital, Daegu, Korea \\ ${ }^{3}$ Department of Obstetrics and Gynecology, School of Medicine, Kyungpook National University, Daegu, Korea \\ ${ }^{4}$ Department of Pediatrics, Kyungpook National University Hospital, School of Medicine, Kyungpook National University, Daegu, Korea
}

Received: June 18, 2020

Revised: September 1, 2020

Accepted: September 4, 2020

Corresponding author:

Mi Ju Kim, MD

Department of Obstetrics and

Gynecology, School of Medicine,

Kyungpook National University, 130

Dongdeok-ro, Jung-gu, Daegu

41944, Korea

Tel: +82-53-420-5724

Fax: +82-53-423-7905

E-mail: ties1004@naver.com
Imperforate anus is an anomaly caused by a defect in the development of the hindgut during early pregnancy. It is a relatively common congenital malformation and is more common in males. Although there are cases of a solitary imperforate anus, the condition is more commonly found as a part of a wider spectrum of other congenital anomalies. Although urgent reconstructive anorectal surgery is not necessary, immediate evaluation is important and urgent decompressive surgery may be required. Moreover, as there are often other anomalies that can affect management, prenatal diagnosis can help in optimizing perinatal care and prepare parents through prenatal counseling. In the past, imperforate anus was diagnosed by prenatal ultrasonography based on indirect signs such as bowel dilatation or intraluminal calcified meconium. Currently, it is diagnosed by directly checking the perineum with prenatal ultrasonography. Despite advances in ultrasound technology, accurate prenatal diagnosis is impossible in most cases and imperforate anus is detected after birth. Here, we present two cases of imperforate anus in female fetuses that were not diagnosed prenatally.

Keywords: Fetus; Imperforate anus; Prenatal diagnosis; Ultrasonography

\section{Introduction}

Imperforate anus is a major form of anorectal malformation wherein the baby is born without a normal anal opening. The incidence of imperforate anus varies from 1:1,500 to 1:5,000 in neonates $[1,2]$. The anomaly is not life-threatening; however, it is likely related to VACTERL association (vertebral anomalies, anal atresia, cardiac defects, tracheoesophageal fistula, esophageal atresia, renal and radial anomalies, and limb defects) or to chromosomal anomalies [3-7]. Early reports of prenatal diagnosis have relied on indirect signs such as bowel dilatation or intraluminal calcified meconium detected with prenatal ultrasonography. Additionally, it is possible to diagnose imperforate anus directly by identifying the normal anus that appears as an external hypoechoic ring with an echogenic center [8-18]. Currently, identifying the type of the imperfo- rate anus was even attempted using ultrasonography prenatally [5]. However, prenatal diagnosis of imperforate anus in a female fetus is still difficult.

\section{Cases}

\section{Case 1}

A 33-year-old primigravida was referred to our tertiary center for fetal congenital heart disease at 21 weeks of gestation. She was healthy, had no medical or surgical history, and was taking folic acid and multivitamin supplements, including iron. She had undergone first and second integrated tests, with results showing a high risk for Down syndrome (1:29). Amniocentesis revealed a normal karyotype. At 20 weeks of gestation, a detailed fetal ultrasonography was performed that showed fetal heart disease, namely tetralo-

Copyright (C) 2021 Yeungnam University College of Medicine

This is an Open Access article distributed under the terms of the Creative Commons Attribution Non-Commercial License (http://creativecommons.org/licenses/by-nc/4.0/) which permits unrestricted non-commercial use, distribution, and reproduction in any medium, provided the original work is properly cited. 
gy of Fallot (TOF). In addition to TOF, a single umbilical artery and fetal toe anomaly (such as clinodactyly) were observed. At 30 weeks of gestation, the fetal anus was thought to be visible because the hypoechogenic area indicating the anal sphincter and hypoechogenic ring showed signs of anal mucosa (Fig. 1). However, the perineal body appeared to be shorter than that of a normal female fetus, which indicated to probability of imperforate anus diagnosis. At 38 weeks and 2 days of gestation, an elective cesarean section was performed and a female $(2,320 \mathrm{~g})$ neonate was born. She was in the 3rd percentile for weight and had an Apgar score of 8 at 1 minute and 9 at 5 minutes. After birth, the female baby was diagnosed with TOF and imperforate anus, with clinodactyly in both the toes. Specifically, the imperforate anus was low-type and accompanied by a vestibular fistula, which was not diagnosed during the prenatal period (Fig. 2). The next day, a sigmoid colon colostomy was performed, and feeding began 2 days later.

\section{Case 2}

A 33-year-old multigravida visited our outpatient clinic for fetal heart anomaly at 23 weeks of gestation. She had undergone a cesarean section 3 years prior and had no medical history. During this pregnancy, she had routine obstetrical examinations and integrated tests, and the results were unremarkable. A detailed fetal ultrasonography was conducted again in our hospital, which suggested a double outlet right ventricle (DORV) with a large ventricular septal defect (VSD). No other anomalies were detected. Further, an ultrasonography of the fetal anus was performed, and the presence of an anal sphincter and anal mucosa was noted; therefore, a fetal imperforate anus was not suspected (Fig. 3). At 38 weeks and

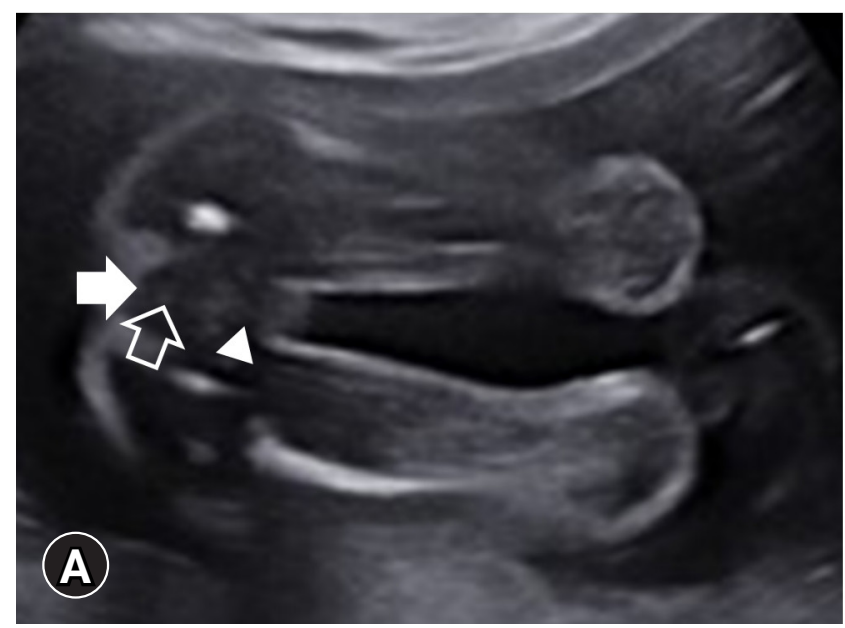

3 days of gestation, an emergency cesarean section was performed due to labor pain, and a female $(2,730 \mathrm{~g})$ neonate was delivered. Operation findings revealed meconium-tinged amniotic fluid, but the baby cried well and was pink in color. She was in the 3rd percentile for weight and had an Apgar score of 7 at 1 minute and 9 at 5 minutes. The umbilical cord had a $\mathrm{pH}$ level of 7.24, indicating that fetal acidosis was absent. After birth, she was diagnosed with DORV with a large VSD and no pulmonary stenosis, as suspected on prenatal ultrasonography. In addition to multiple heart anomalies, she was diagnosed with imperforate anus after birth. The imperforate anus was a low-type with a vestibular fistula. The day after delivery, a sigmoid colon colostomy was performed. The baby

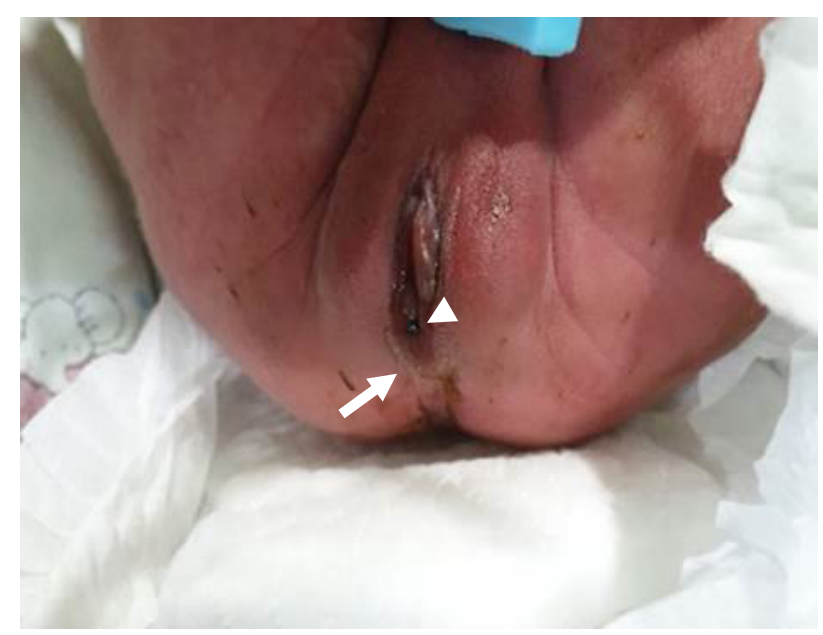

Fig. 2. Postnatal finding of case 1. No anal opening in the original location is present (arrow). A vestibular fistula is accompanied (arrowhead).

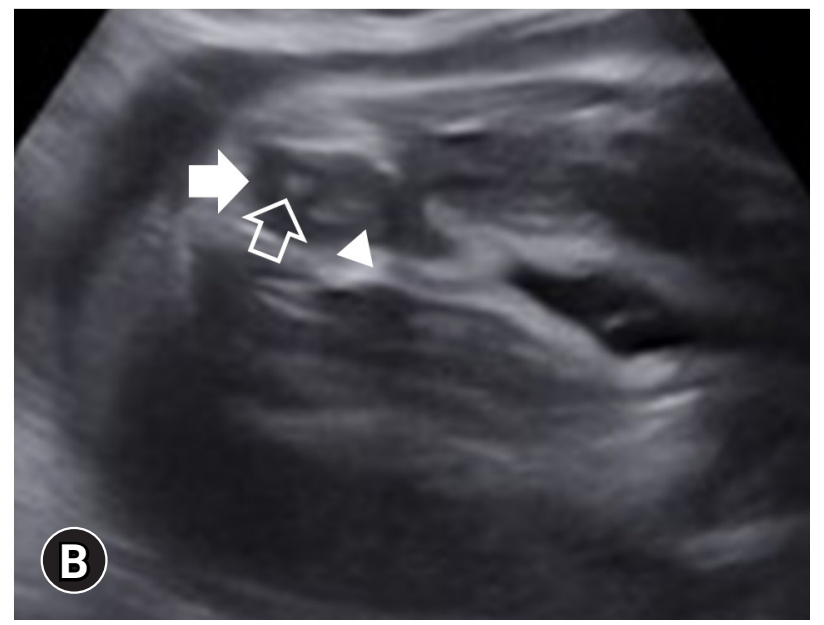

Fig. 1. The images of fetal ultrasonography of case 1. (A) At 30 weeks of gestation, there is an echogenic ring (open arrow) in the hypoechogenic area (solid arrow), suggesting an intact anus with a rather short perineal body (arrowhead). (B) At 35 weeks of gestation, a short perineal body (arrowhead) is revealed, and an echogenic ring (open arrow) indicating the anal mucosa in the hypoechogenic area (solid arrow) is seen. 


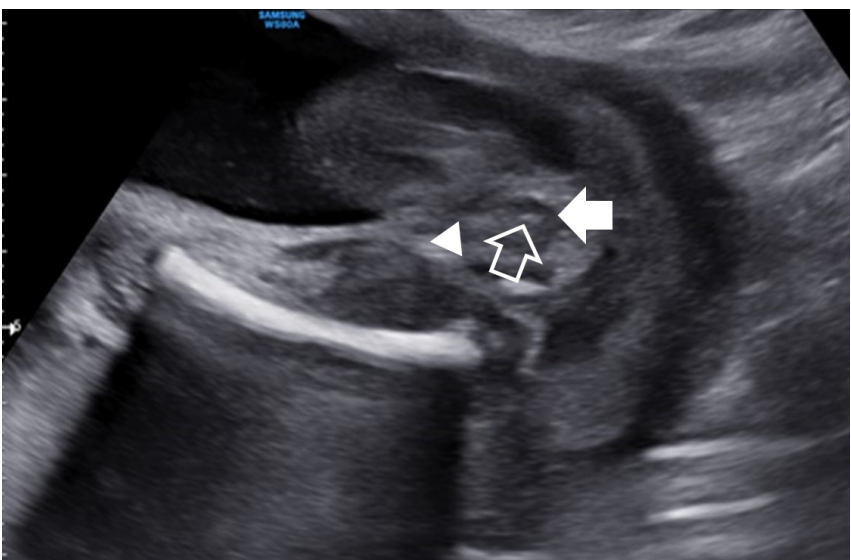

Fig. 3. The image of fetal ultrasonography of case 2. At 30 weeks of gestation, the perineum is seen, and an intact anus is suspected because of the hyperechogenic ring indicating anal mucosa (open arrow) in normal sphincter muscles (solid arrow), despite the short perineal body (arrowhead). After birth, the baby was diagnosed with a low-type imperforate anus with a vestibular fistula.

recovered well, and feeding began 2 days later.

\section{Discussion}

Imperforate anus is a common congenital anomaly with an incidence of $1: 1,500$ to $1: 5,000$ in neonates [1,2]. It may either be a solitary anomaly without any malformation or, in many cases, be associated with multiple congenital anomaly subsets, such as VACTERL association or trisomy 21 [3-7]. Imperforate anus, with other serious anomalies, can lead to significant morbidity and mortality.

Although imperforate anus is a relatively common malformation, it cannot be accurately diagnosed prenatally. Imperforate anus can occur as a solitary abnormality but is likely to have accompanying malformations. Hence, diagnosed with a fetal imperforate anus should be referred to a tertiary center that can provide accurate diagnosis and adequate management. Conversely, even if one malformation associated with VACTERL association is detected prenatally, more detailed ultrasonography examinations should be performed regarding the presence of imperforate anus. Even without considering other accompanying anomalies (except imperforate anus), the exact anatomical type of atresia and the existence of a fistula should be carefully examined. This is important because it determines the appropriate timing for corrective surgery as well as the surgical stages. Urgent reconstructive anorectal surgery is not necessary; however, immediate evaluation is important, and urgent decompressive surgery may be necessary. If a diagnosis is suspected prenatally, it is essential for the surgeon to provide appropriate guidance to the pregnant woman and to make a delivery plan to prepare for the possibility of neonatal operation [2]. Thus, detecting the presence of an imperforate anus via prenatal ultrasonography is important for obstetricians, pediatric surgeons, and pregnant women to plan for an early treatment.

There are three types of imperforate anus according to the distal rectal pouch and the puborectalis muscle [5]: (1) the high-type, in which the distal pouch ends above the puborectalis muscle; (2) the intermediate-type, in which the pouch ends at the puborectalis muscle; and (3) the low-type, in which the pouch ends through the puborectalis muscle [5]. Traditionally, imperforate anus is diagnosed by prenatal ultrasound on detecting the presence of a dilated distal bowel, or rectum or intraluminal meconium calcification, or enterolithiasis [8-17]; however, it is not always suspected with the presence of a fistula. After the 1990s, improvements in ultrasound resolution have helped in visualizing the fetal perineum and detecting the hypoechogenic ring indicating the perianal muscular complex (PAMC), namely the internal anal sphincter, puborectalis muscle, and external sphincter with an echogenic center, which indicates anal mucosa [18]. Nevertheless, care should be taken to distinguish the two components of the sonographic sign, anal mucosa and muscular components, to avoid misdiagnosis of a perineal fistula, which may be seen as the adequate development of the PAMC is expected in low imperforated anus [19]. A recent study suggested that a low-type imperforate anus is suspected if the size of the anus is small or the distance between the anus and the genitalia is short [5]. The high-type imperforate anus, however, is relatively well diagnosed during pregnancy and is more frequently found in male infants, with a higher mortality and morbidity compared to other types [5]. In contrast, low-type is more common in female fetuses, with a relatively good prognosis; however, it is difficult to recognize in the prenatal period.

In this study, the two neonates were diagnosed with congenital heart disease prenatally and were diagnosed with imperforate anus with vestibular fistula postnatally. Bowel dilatation was not observed; however, a decompressed obstructed bowel due to the presence of a fistula was noted [11]. Ultrasonographic findings revealed an anatomic structure in the PAMC, indicating the anal sphincter, anal mucosa, and a relatively short perineal body with other combined anomalies. These findings should have been regarded as a clue to diagnose an imperforate anus with or without fistula.

If any fetal anomaly is detected, the fetal anus should be examined since an imperforate anus is commonly associated with other anomalies. An imperforate anus is still difficult to diagnose in some cases, and as observed in these two female fetuses, a fistula makes the diagnosis difficult because it does not typically represent the 
imperforate anus. Although it is possible to diagnose incomplete anus by directly visualizing the perineum of the fetus using ultrasonography, prenatal diagnosis of imperforate anus remains challenging, especially in female fetuses with a low-type imperforate anus. Even after birth, a close physical examination of the baby is necessary as the passage of meconium alone is not a sign of a correctly positioned anus because the presence of the fistula makes it possible to pass meconium.

Even if the structure of the anus appears normal, it is important to accurately identify the anus in female fetuses with other accompanying anomalies. Detailed prenatal ultrasonography and reasonable suspicion of imperforate anus based on images can increase the accuracy of the diagnosis. This can help counsel parents regarding the prognosis of the fetus by providing accurate information.

\section{Notes}

\section{Ethical statements}

This study was approved by the Institutional Review Board (IRB) of the Kyungpook National University Chilgok Hospital (IRB No: 2020-06-031). Written informed consent was obtained from the parent/guardian for publication of this case report and accompanying images.

\section{Conflicts of interest}

No potential conflict of interest relevant to this article was reported.

\section{Author contributions}

Conceptualization, Project administration: WJS; Data curation: MJK; Formal analysis: SHP; Methodology: MJK, SHP; Visualization: SHP, HHC; Investigation: HMK, HHC; Resources: WJS, JIK; Software: HMK; Supervision: JIK; Validation: HHC, JIK; Writing-original draft: MJK; Writing-review \& editing: HMK.

\section{ORCID}

Hyun Mi Kim, https://orcid.org/0000-0002-2985-9965

Hyun-Hwa Cha, https://orcid.org/0000-0002-4399-7627

Jong In Kim, https://orcid.org/0000-0002-7146-4369

Won Joon Seong, https://orcid.org/0000-0002-8088-2554

Sook-Hyun Park, https://orcid.org/0000-0002-4782-1127

Mi Ju Kim, https://orcid.org/0000-0001-9770-1580

\section{References}

1. Cuschieri A; EUROCAT Working Group. Anorectal anomalies associated with or as part of other anomalies. Am J Med Genet
2002;110:122-30.

2. Brantberg A, Blaas HG, Haugen SE, Isaksen CV, Eik-Nes SH. Imperforate anus: a relatively common anomaly rarely diagnosed prenatally. Ultrasound Obstet Gynecol 2006;28:904-10.

3. Cho S, Moore SP, Fangman T. One hundred three consecutive patients with anorectal malformations and their associated anomalies. Arch Pediatr Adolesc Med 2001;155:587-91.

4. Stoll C, Alembik Y, Dott B, Roth MP. Associated malformations in patients with anorectal anomalies. Eur J Med Genet 2007; 50:281-90.

5. Lee MY, Won HS, Shim JY, Lee PR, Kim A, Lee BS, et al. Sonographic determination of type in a fetal imperforate anus. J Ultrasound Med 2016;35:1285-91.

6. Black CT, Sherman JO. The association of low imperforate anus and Down's syndrome.J Pediatr Surg 1989;24:92-4.

7. Torres R, Levitt MA, Tovilla JM, Rodriguez G, Peña A. Anorectal malformations and Down's syndrome. J Pediatr Surg 1998; 33:194-7.

8. Bean WJ, Calonje MA, Aprill CN, Geshner J. Anal atresia: a prenatal ultrasound diagnosis. J Clin Ultrasound 1978;6:111-2.

9. Taipale P, Rovamo L, Hiilesmaa V. First-trimester diagnosis of imperforate anus. Ultrasound Obstet Gynecol 2005;25:187-8.

10. Harris RD, Nyberg DA, Mack LA, Weinberger E. Anorectal atresia: prenatal sonographic diagnosis. AJR Am J Roentgenol 1987;149:395-400.

11. Hearn-Stebbins B, Sherer DM, Abramowicz JS, Hess HM, Woods JR Jr. Prenatal sonographic features associated with an imperforate anus and rectourethral fistula. J Clin Ultrasound 1991;19:508-12.

12. Bronshtein M, Zimmer EZ. Early sonographic detection of fetal intestinal obstruction and possible diagnostic pitfalls. Prenat Diagn 1996;16:203-6.

13. Grant T, Newman M, Gould R, Schey W, Perry R, Brandt T. Intraluminal colonic calcifications associated with anorectal atresia: prenatal sonographic detection. J Ultrasound Med 1990; 9:411-3

14. Mandell J, Lillehei CW, Greene M, Benacerraf BR. The prenatal diagnosis of imperforate anus with rectourinary fistula: dilated fetal colon with enterolithiasis. J Pediatr Surg 1992;27:82-4.

15. Shalev E, Weiner E, Zuckerman H. Prenatal ultrasound diagnosis of intestinal calcifications with imperforate anus. Acta Obstet Gynecol Scand 1983;62:95-6.

16. Lubusky M, Prochazka M, Dhaifalah I, Horak D, Geierova M, Santavy J. Fetal enterolithiasis: prenatal sonographic and MRI diagnosis in two cases of urorectal septum malformation (URSM) sequence. Prenat Diagn 2006;26:345-9.

17. Shimotake T, Higuchi K, Tsuda T, Aoi S, Iwai N. Infrared spec- 
trophotometry of intraluminal meconium calculi in a neonate with imperforate anus and rectourethral fistula. J Pediatr Surg 2006;41:1173-6.

18. Guzman ER, Ranzini A, Day-Salvatore D, Weinberger B, Spigland N, Vintzileos A. The prenatal ultrasonographic visualization of imperforate anus in monoamniotic twins. J Ultra- sound Med 1995; 14:547-51.

19. Ochoa JH, Chiesa M, Vildoza RP, Wong AE, Sepulveda W. Evaluation of the perianal muscular complex in the prenatal diagnosis of anorectal atresia in a high-risk population. Ultrasound Obstet Gynecol 2012;39:521-7. 